\title{
High performance obtained with no reward'
}

\section{LUCI PAUL, Temple University, Philadelphia, Pa 19122}

Rats attained high runining speeds on a long series of nonrewarded trials, with or without previous reward. Nonrewarded running appeared "playful." Possible motivators and the differences between rewarded and nonrewarded behavior were discussed.

In a pilot study rats were trained to run for food, then were given 200 nonrewarded trials. Running speeds on the nonrewarded trials first decreased, but then increased to the speed previously attained after 200 rewarded trials. The present experiment (a) confirms this unusual relationship between running speed and number of nonrewarded trials, (b) shows that high running speeds after many nonrewarded trials are not a function of prior percentage of reward, and (c) shows high running speeds in rats never given reward.

\section{SUBJECTS}

Fifty-four naive, 100 to 200-day-old male, Sprague-Dawley rats served as Ss. Housed in pairs, the rats were randomly assigned to six experimental groups of nine Ss per group.

\section{APPARATUS}

The alley was $34 \times 4 \times 4$ in., of gray wood with clear Plexiglas top. Either large $(8 \times 8 \times 8$ in. $)$ or small ( $8 \times 4 \times 4$ in.) boxes of gray wood with clear tops were placed at both ends of the alley. Each endbox had a dispenser for 79-mg food pellets. A photocell was placed 1 in. in front of each endbox, and, with proper circuiting, permitted measurement of running times.

\section{PROCEDURE}

Subjects were tamed and placed on a 22-h food-deprivation schedule with ad lib water. Throughout the experiment, 1-h after the daily session, Ss were fed for $1 \mathrm{~h}$.

On each of four pretraining days, Ss were placed in a closed endbox for $15 \mathrm{~min}$. Ss scheduled for reward training were given food pellets in the endbox; Ss not scheduled for reward training were not given pellets.

On each of the experimental days that followed Ss were allowed to shuttle back and forth between the two endboxes for a specified number of trials. A trial was defined as a run from one endbox to the opposite endbox, i.e., a one-way shuttle. Ss were not confined in the endbox on any trial. Following completion of the last trial of a day, a guillotine door between the alley and endbox was lowered and $\mathrm{S}$ was immediately removed from the endbox to its home cage. Ss received 4 trials the first day, 6 trials the second, 10 trials on the third, fourth, and fifth days, and 20 trials a day thereafter, until 500 trials had been run.

The experimental design was a 2 by 3 factorial for endbox size (large or small) and percentage of reward on the first 200 trials $(0 \%, 50 \%$, or $100 \%)$. Ss in the $100 \%$ reward groups were given one food pellet after each of the first 200 trials, then received 300 trials without reward. Ss in the $50 \%$ reward groups received one food pellet, always given in the same endbox, on each of the even-numbered trials of the initial 200 trials, then received 300 trials without reward. Food was never present at the initiation of the first trial of the day. The $0 \%$ reward groups were given 500 trials without food reward.

The time between the last break of the photocell at one end of the alley to the first break of the photocell at the opposite end of the alley was the running-time measure.

\section{RESULTS}

Only one S (100\% reward, large endbox) met a 5-min nonresponse criterion. Its data are not included.
The mean reciprocal running times for each group on blocks of 20 trials are shown in Fig. 1. The four reward groups showed a decrease in speed following removal of reward. However, after 120 nonrewarded trials their speeds increased. Combining all groups for Trial Blocks 11 to 25 , a significant quadratic trend across trials was obtained $(F=8.75$, df $=1 / 336, p<.001$ ) along with a nonsignificant linear trend $(\mathrm{F}=1.37)$.

The mean speed of each group on its last 40 rewarded trials was faster than the same group's speed on its last 40 nonrewarded trials. Only once (50\% reward, large endbox) did a $t$ test fail to show a significantly $(p<.05)$ higher speed on the last $\mathbf{4 0}$ rewarded trials.

Speeds of the two $0 \%$ reward groups gradually increased to a level comparable to terminal rewarded speeds. Only once ( $0 \%$ vs $100 \%$, small endbox) was the speed on any group on their last 40 rewarded trials reliably greater than the speed of either $0 \%$ reward group $(t=4.87, \mathrm{df}=16, \mathrm{p}<.01)$.

Comparing performance between all six groups on the last 40 nonrewarded trials, running speeds were higher with a large endbox $(F=7.85$, df $=1 / 48, p<.01)$, but other betweengroup comparisons were not significant.

In contrast to rewarded running, nonrewarded running was "playful." Typically, the rat would dart its head into the alley, draw back with a hop, pause briefly, then bolt down the alley. On many trials Ss hopped in a full circle before their run. The running itself is better described as bounding, and was so pronounced that $S s$ occasionally bumped against the alley cover.

\section{DISCUSSION}

Fast running can be obtained over a long series of nonrewarded trials, whether or not Ss have had previous experience with rewarded running. The "playful" characteristics of nonrewarded running suggest that it is "intrinsically"
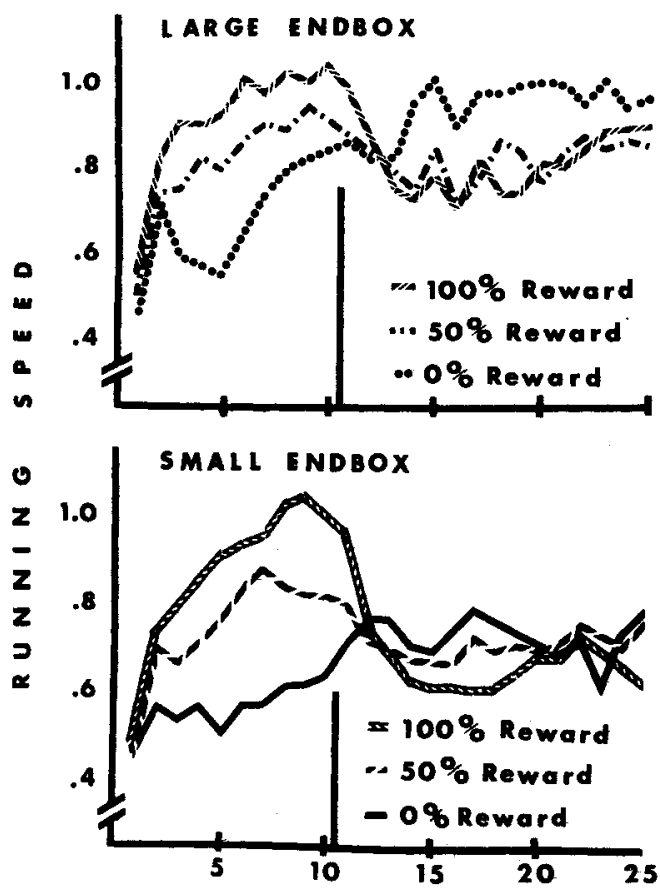

Fig. 1. Mean reciprocal running time on blocks of 20 trials. 
after leaving the startbox. The animals treated with $7 \mathrm{mg} / \mathrm{kg}$ caffeine and $20 \mathrm{mg} / \mathrm{kg}$ magnesium pemoline were also unable to complete the task in the allotted time.

These results suggest that magnesium pemoline's effect is not different from that of a CNS stimulant (caffeine) and both can facilitate the acquisition of a positively reinforced discrimination. The dose response effects for both drugs were nonlinear, showing an optimal dose for the facilitation of acquisition in our apparatus.

The failure of the picrotoxin-treated animals to run in the T-maze is at present unexplainable. Pretrial injections of the drug have been used successfully in an appetitive maze learning situation (Prien et al, 1963). McGaugh (1967) has stated that the effect of a given drug on learning varies with the drug dose, age, apparatus, strain, and sex of the animals used.

While several possible mechanisms such as stimulus reactivity (Beach \& Kimble, 1967) or stimulant-enhanced consolidation (McGaugh, 1967) may explain the magnesium pemoline and caffeine data, more information of a comparative nature concerning the effects of both analeptics and RNA enhancers on learning is necessary.

\section{REFERENCES}

BEACH, G., \& KIMBLE, D. Activity and responsivity in rats after magnesium pemoline injections. Science, 1967, 155, 698-701.

FILBY, Y., SZARA, S., \& SALZMAN, B. Magnesium pemoline: Effect on acquisition and retention of discriminated avoidance behavior. Psychonomic Science, 1967, 9, 131-132.
FREY, P., \& POLIDORA, V. Magnesium pemoline: Effect on avoidance conditioning in rats. Science, 1967, 155, 1281-1282.

GLASKY, A., \& SIMON, L. Magnesium pemoline: Enhancement of brain RNA polymerases. Science, 1966, 151, 702-703.

KULKARNI, A. Magnesium pemoline: Facilitation of instrumental avoidance learning. Psychonomic Science, 1967, 9, 39-40.

LUBAR, J., BOITANO, J., GUROWITZ, E., \& AIN, B. Enhancement of performance in the Hebb-Williams maze by magnesium pemoline. Psychonomic Science, 1967, 7, 381-382.

McGAUGH, J. Drug facilitation of memory and learning. Paper presented at the Sixth Annual Meeting of the American College of Neuropsychopharmacology, San Juan, Puerto Rico, 1967.

MORRIS, N., AGHAJANIAN, G., \& BLOOM, F. Magnesium pemoline: Failure to affect in vivo synthesis of brain RNA. Science, 1967, 155, 1125-1126.

PLOTNIKOFF, N. Magnesium pemoline: Enhancement of learning and memory of a conditioned avoidance response. Science, 1966, 151, 703-704.

POTTS, W. J. An investigation of drug effects on learning and memory in rats. Unpublished doctoral dissertation, 1968.

PRIEN, R., WAGNER, M., \& KAHAN, S. Lack of facilitation in maze learning by picrotoxin and strychnine sulphate. American Journal of Phy siology, 1963, 204, 488-492.

SIMON, L., \& GLASKY, A. Magnesium pemoline: Enhancement of brain RNA synthesis in vivo. Life Sciences, 1968, 7, 197-202. NOTES

1. Supported in part by David Ross Grant PRF 5069, Purdue Research Foundation, and MH 14156-01, National Institute of Mental Health to W.C.B. W.J.P. and D.L.M. were National Institute of Mental Health predoctoral fellows, 1-F1-MH 30331 and 1-F1-MH 37435, respectively.

2. Present address: G. D. Searle Co., Chicago, Illinois.

3. Present address: State University of New York, New Paltz, New York.

\section{(Continued from page 224)}

motivated, performed for its own sake rather than for some extrinsic goal (Koch, 1956). However, potential "extrinsic" incentives were present, i.e., auditory reinforcement from clicks produced by passage through the photocells, visual stimulation, handling, return to home cage, and feeding 1-h later. It is unlikely that such incentives produced the behavior because none were contingent on running.

Others have reported well-maintained, nonrewarded running. Clark \& Miller (1966) found fast, nonrewarded running following rewarded runs in a $\mathrm{T}$-maze and attributed their finding to use of a very short intertrial interval. In Logan's study (1960) of "operant-level" running in an alley, rats, given one trial a day, never failed to run, but their running was quite slow. Logan attributed the maintenance of running without reward to use of a very long intertrial interval, food deprivation, and confinement in small cages. The procedural differences between the present study and those of Clark and Miller, and Logan are too great to permit a statement concerning the conditions necessary to produce continued, nonrewarded running.

A feature of the present research is that it permits a comparison of the same gross response under rewarded and nonrewarded conditions. First, nonrewarded running can be as fast as rewarded running. Nonrewarded running is faster with a large endbox than with a small one, possibly because the large endbox permits more "playful" behavior. Second, because speeds were depressed for a large number of trials following food reward, fast nonrewarded running is probably not a case of positive transfer from prior reward conditions to nonreward conditions. In the previously rewarded groups, the U-shaped function obtained on nonrewarded trials may reflect a change from "extrinsic" to "intrinsic" motivation. Third, speeds (and, from observation, the amount of "playful" behavior) on nonrewarded trials gradually increased, resembling an acquisition function obtained with reward, suggesting either the acquisition of $S-R$ connections or increased incentive value with repeated experience. Fourth, peak performance without reward required many more trials to achieve than with reward, indicating either that the reinforcement for nonrewarded running is weaker than food reward, or that "intrinsic" motivation develops quite gradually. Fifth, terminal nonrewarded performance was unaffected by the previous schedule of reward. Perhaps the variables regulating "intrinsically"-motivated behavior are not the same as those regulating "extrinsically"-motivated behavior.

\section{REFERENCES}

CLARK, J. W., \& MILLER, S. B. The development of rapid running in T-mazes in the absence of obvious rewards. Psychonomic Science, $1966,4,127-128$.

$\mathrm{KOCH}, \mathrm{S}$. Behavior as "intrinsically" regulated: Work notes towards a pre-theory of phenomena called "motivational." In M. R. Jones (Ed.), Nebraska symposium on motivation. Lincoln: University of Nebraska Press, 1956.

LOGAN, F. A. Incentive. New Haven: Yale University Press, 1960 NOTE

1. Based on a portion of a Ph.D. dissertation submitted to the Department of Psychology, University of Pittsburgh. The author expresses appreciation to J. Trevor Peirce for his guidance of the research. 